\title{
Electrophysiological and Behavioral Responses of an Ambrosia Beetle to Volatiles of its Nutritional Fungal Symbiont
}

\author{
Christopher M. Ranger ${ }^{1}$ (D) $\cdot$ Marek Dzurenko $^{2,3}$. Jenny Barnett ${ }^{1} \cdot$ Ruchika Geedi $^{1} \cdot$ Louela Castrillo $^{4}$. \\ Matthew Ethington ${ }^{5} \cdot$ Matthew Ginzel $^{5,6} \cdot$ Karla Addesso $^{7} \cdot$ Michael E. Reding $^{1}$
}

Received: 17 December 2020 / Revised: 23 February 2021 / Accepted: 2 March 2021 / Published online: 24 March 2021

(C) This is a U.S. government work and not under copyright protection in the U.S.; foreign copyright protection may apply 2021

\begin{abstract}
Ambrosia beetles (Coleoptera: Scolytinae) cultivate their fungal symbiont within host substrates as the sole source of nutrition on which the larvae and adults must feed. To investigate a possible role for semiochemicals in this interaction, we characterized electrophysiological and behavioral responses of Xylosandrus germanus to volatiles associated with its fungal symbiont Ambrosiella grosmanniae. During still-air walking bioassays, $X$. germanus exhibited an arrestment response to volatiles of A. grosmanniae, but not antagonistic fungi Beauveria bassiana, Metarhizium brunneum, Trichoderma harzianum, the plant pathogen Fusarium proliferatum, or malt extract agar. Solid phase microextraction-gas chromatography-mass spectrometry identified 2-ethyl-1-hexanol, 2-phenylethanol, methyl benzoate and 3-methyl-1-butanol in emissions from A. grosmanniae; the latter two compounds were also detected in emissions from $B$. bassiana. Concentration-responses using electroantennography documented weak depolarizations to A. grosmanniae fungal volatiles, unlike the comparatively strong response to ethanol. When tested singly in walking bioassays, volatiles identified from A. grosmanniae elicited relatively weak arrestment responses, unlike the responses to ethanol. Xylosandrus germanus also exhibited weak or no long-range attraction to the fungal volatiles when tested singly during field trials in 2016-2018. None of the fungal volatiles enhanced attraction of $X$. germanus to ethanol when tested singly; in contrast, 2-phenylethanol and 3-methyl-1-butanol consistently reduced attraction to ethanol. Volatiles emitted by A. grosmanniae may represent short-range olfactory cues that could aid in distinguishing their nutritional fungal symbiont from other fungi, but these compounds are not likely to be useful as long-range attractants for improving detection or mass trapping tactics.
\end{abstract}

Keywords Xylosandrus germanus $\cdot$ Ambrosiella grosmanniae $\cdot$ Symbiosis $\cdot$ Fungal volatiles

Christopher M. Ranger

christopher.ranger@usda.gov

1 Horticultural Insects Research Laboratory, USDA-Agricultural Research Service, 1680 Madison Ave, Wooster, OH 44691, USA

2 Slovak Academy of Sciences, Institute of Forest Ecology, L'udovíta Štúra 2, 96053 Zvolen, Slovakia

3 Present Address: Department of Integrated Forest and Landscape Protection, Technical University in Zvolen, Ul. T. G. Masaryka 24, 96001 Zvolen, Slovakia

4 Emerging Pests and Pathogens Research, USDA-Agricultural Research Service, Ithaca, NY 14853-2901, USA

5 Department of Entomology, Purdue University, 901 W. State Street, West Lafayette, IN 47907, USA

6 Department of Forestry and Natural Resources, Purdue University, 715 W. State Street, West Lafayette, IN 47907, USA

7 Otis L. Floyd Nursery Research Center, College of Agriculture, Tennessee State University, McMinnville, TN 37110, USA

\section{Introduction}

Ambrosia beetles (Curculionidae: Scolytinae and Platypodinae) are characterized by their obligate symbiosis with fungi (Hulcr et al. 2015). Thirty of the 60 exotic Scolytinae established in North America are within the tribe Xyleborini, which includes many species that attack horticultural trees (Agnello et al. 2017; Gomez et al. 2018; Hulcr and Stelinski 2017; Ranger et al. 2016). Dispersing female xyleborine beetles carry spores of their fungal symbiont(s) within mycetangia in the form of pits, grooves, sacs, or invaginated pouches (Hulcr et al. 2015; Vega and Biedermann 2020). The fungal symbionts are mainly in the genera Ambrosiella, Fusarium, and Raffaelea and rely on ambrosia beetles for dispersal and propagation (Kostovcik et al. 2015; Mayers et al. 2015; Wingfield et al. 2017). During tunnel excavation by female xyleborine beetles into host trees, spores are transferred to the tunnel walls for establishing fungal 
gardens (Batra 1985). Females begin ovipositing eggs after sowing the fungal symbiont that serves as the sole source of nourishment for developing larvae and maturing adults (Biedermann and Taborsky 2011).

Xylosandrus germanus is a xyleborine ambrosia beetle native to southeast Asia but now established throughout much of Europe and North America (Dzurenko et al. 2021; Gomez et al. 2018). Male $X$. germanus are flightless, do not possess a mycetangium, and remain in or near their natal gallery for life; females disperse to initiate new colonies and attack recently cut logs, saplings, and mature trees of more than 200 species in managed and unmanaged systems (Galko et al. 2018; Ranger et al. 2016, 2021). Thin-barked deciduous species are commonly selected in horticultural systems, but coniferous species are also attacked. Despite a broad host range, living but weakened trees in the early stages of physiological stress are preferentially attacked by $X$. germanus while healthy trees are rarely attacked and poorly colonized (Ranger et al. 2015). A variety of factors can predispose trees to attack by $X$. germanus, including flood and low temperature stress (Ranger et al. 2021).

During host-selection, ethanol represents an important long-range attractant and host acceptance cue used by $X$. germanus to locate suitable trees for establishing their nutritional symbiont Ambrosiella grosmanniae and rearing offspring (Klimetzek et al. 1986; Ranger et al. 2021; Rassati et al. 2020). Ethanol also promotes the growth of A. grosmanniae, and its presence within host tissues increases the colonization success of $X$. germanus (Ranger et al. 2018). Ethanol is induced and emitted from the epidermis of trees in response to the aforementioned stressors and a variety of other abiotic and biotic factors (Kimmerer and Kozlowski 1982; Ranger et al. 2021). Other host-derived compounds tested to date were weak and inconsistent attractants for X. germanus when tested alone or in combination with ethanol, including an alcohol (i.e. methanol), aldehyde (i.e. acetaldehyde), ketone (i.e. acetone), spiroacetal (i.e. conophthorin), and several monoterpenes (i.e. $\alpha$ - and $\beta$-pinene, camphene, myrcene, $\rho$-cymene, limonene, and eucalyptol) (Dodds and Miller 2010; Kohnle et al. 1992; Miller et al. 2015; Ranger et al. 2010, 2011, 2014; VanDerLaan and Ginzel 2013). There is currently no evidence that $X$. germanus or other xyleborines produce a long-range aggregation or sex pheromone, perhaps because males are flightless and females reproduce through haplodiploidy (Ott 2007; Ranger et al. 2021).

A growing body of research indicates that insects respond to fungal volatile organic compounds associated with their sensory environment, but few fungal volatiles have been tested to date for activity in laboratory or natural settings (Davis et al. 2013). As fungus farming insects, ambrosia beetles represent a promising model system for symbiosis due to their close association with fungal species. During olfactometer studies, Hulcr et al. (2011) demonstrated that three species of ambrosia beetles were attracted to volatiles emitted from the mycelium of their fungal symbionts, namely, Xyleborus glabratus and Raffaelea lauricola, Xyleborus ferrugineus and Ambrosiozyma ambrosiae, and Xylosandrus crassiusculus and Ambrosiella roeperi. In contrast, the aforementioned species were non-responsive or repelled by mycoparasitic Trichoderma sp. Olfactometer studies conducted by Egonyu and Torto (2018) also observed that Xylosandrus compactus was attracted to volatiles emitted from mycelium of its symbiont Fusarium solani (Mart.) Sacc. Characterizing ambrosia beetle semiochemicals emitted by their fungal symbiont could provide insight into the evolutionary and ecological basis for such chemical signals. A specific and conserved association has been documented among populations of $X$. germanus and A. grosmanniae (Mayers et al. 2015), but other ambrosia beetles are associated with multiple different fungi (Kostovcik et al. 2015). Identifying these semiochemicals might also enhance attraction to existing lures for detecting and monitoring destructive ambrosia beetles.

The overall goal of our current study was to characterize the response of $X$. germanus to volatiles associated with its fungal symbiont $A$. grosmanniae. We hypothesized that $X$. germanus would exhibit short- and/or long-range behavioral responses to volatiles associated with $A$. grosmanniae due to their close evolutionary and ecological associations. To test this hypothesis, the specific objectives were to: (1) compare the short-range arrestant response of $X$. germanus to volatiles emitted from A. grosmanniae relative to the entomopathogenic fungi Beauveria bassiana and Metarhizium brunneum, the mycoparasitic fungus Trichoderma harzianum, and the plant pathogen Fusarium proliferatum; (2) identify volatiles emitted from A. grosmanniae and the aforementioned fungi by solid phase microextraction-gas chromatography-mass spectrometry (SPME-GC-MS); (3) characterize olfactory responses of $X$. germanus by means of electroantennography (EAG) to A. grosmanniae fungal volatiles; and (4) evaluate the short- and long-range behavioral response of $X$. germanus to A. grosmanniae fungal volatiles.

\section{Methods and Materials}

\section{Culturing of $A$. grosmanniae}

Adult female $X$. germanus were collected after dispersing from their overwintering galleries within host tree substrates using bottle traps (Ranger et al. 2010). Traps were baited with an ethanol sachet lure $\left(65 \mathrm{mg} / \mathrm{d}\right.$ at $30{ }^{\circ} \mathrm{C}$; AgBio, Inc., Westminster, $\mathrm{CO}$ ) and deployed in a mixed hardwood forested area at the Ohio Agricultural Research and Development Center in Wayne Co., Ohio, USA $\left(40^{\circ} 45^{\prime} 40.85^{\prime} \mathrm{N}, 81^{\circ} 51^{\prime}\right.$ 14.71 'W). Adults collected in the traps were prevented from desiccating by placing a moistened paper towel rolled into a 
tube in the bottom collection vessel of the trap (Ranger et al. 2015). Trap contents were collected daily and transferred to parafilm-sealed petri dishes containing moistened filter paper and stored for 24 to $48 \mathrm{~h}$ at $3.3^{\circ} \mathrm{C}$. Field collected beetles were then surface sterilized by briefly ( $2-3 \mathrm{~s}$ ) dipping in $70 \%$ ethanol (aq). Under a laminar flow hood, a sterile transfer needle was next inserted into the thoracic mycetangia of $X$. germanus and streaked onto petri dishes containing $2 \%$ malt extract agar. A representative cultured strain isolated from beetles field collected beetles in Shreve, Ohio, USA $\left(40^{\circ} 41^{\prime} 36.24\right.$ 'N; $81^{\circ} 55^{\prime} 31.59^{\prime} \mathrm{W}$ ) in May 2010 and designated as $\mathrm{XgOH} 11$ was used (Castrillo et al. 2016; Mayers et al. 2015).

\section{Behavioral Bioassay}

A still-air walking olfactometer (Fig. 1a, b) described by Borden et al. (1968) was used to assess the behavioral responses of $X$. germanus to volatiles of its fungal symbiont, A. grosmanniae, as compared to the entomopathogenic fungi Beauveria bassiana (Balsamo) Vuillemin strain GHA and Metarhizium brunneum Petch strain F52 (=ARSEF 5198; previously identified as Metarhizium anisopliae), the mycoparasitic fungus Trichoderma harzianum Rifai strain T-22, and the plant pathogen Fusarium proliferatum (Matsushima) Nirenberg as representative of a non-symbiont and non-entomopathogen. All fungal strains are maintained under long-term storage at the USDA-ARS Robert W. Holley Center for Agriculture \& Health in Ithaca, NY (Castrillo et al. 2016).

The still-air olfactometer consisted of a Plexiglas acrylic platform $(36 \times 10 \mathrm{~cm} ; \mathrm{L} \times \mathrm{W})$ on which ambrosia beetles could walk that included two rectangular openings $(5 \times 2.5 \mathrm{~cm}$; $\mathrm{L} \times \mathrm{W})$ positioned $10 \mathrm{~cm}$ from either end (Fig. 1a, b). Fine mesh polyester fabric $\left(35 \times 35\right.$ squares $\left./ \mathrm{cm}^{2}\right)$ was secured tightly across the surface of the platform using medium size binder clips $(3.17 \mathrm{~cm}$ width; $1.6 \mathrm{~cm}$ clip capacity) to provide traction for beetles while walking and to allow beetles to pass over the two rectangular openings. The platform was then rested on two uncovered polystyrene petri dishes so the two rectangular openings were positioned directly over the open petri dishes. In doing so, volatiles could emanate upwards from the petri dishes and through the mesh-covered rectangular openings. The petri dish positioned on the right-hand side of the observer was empty and not used for measuring behavioral responses during all bioassays, while the
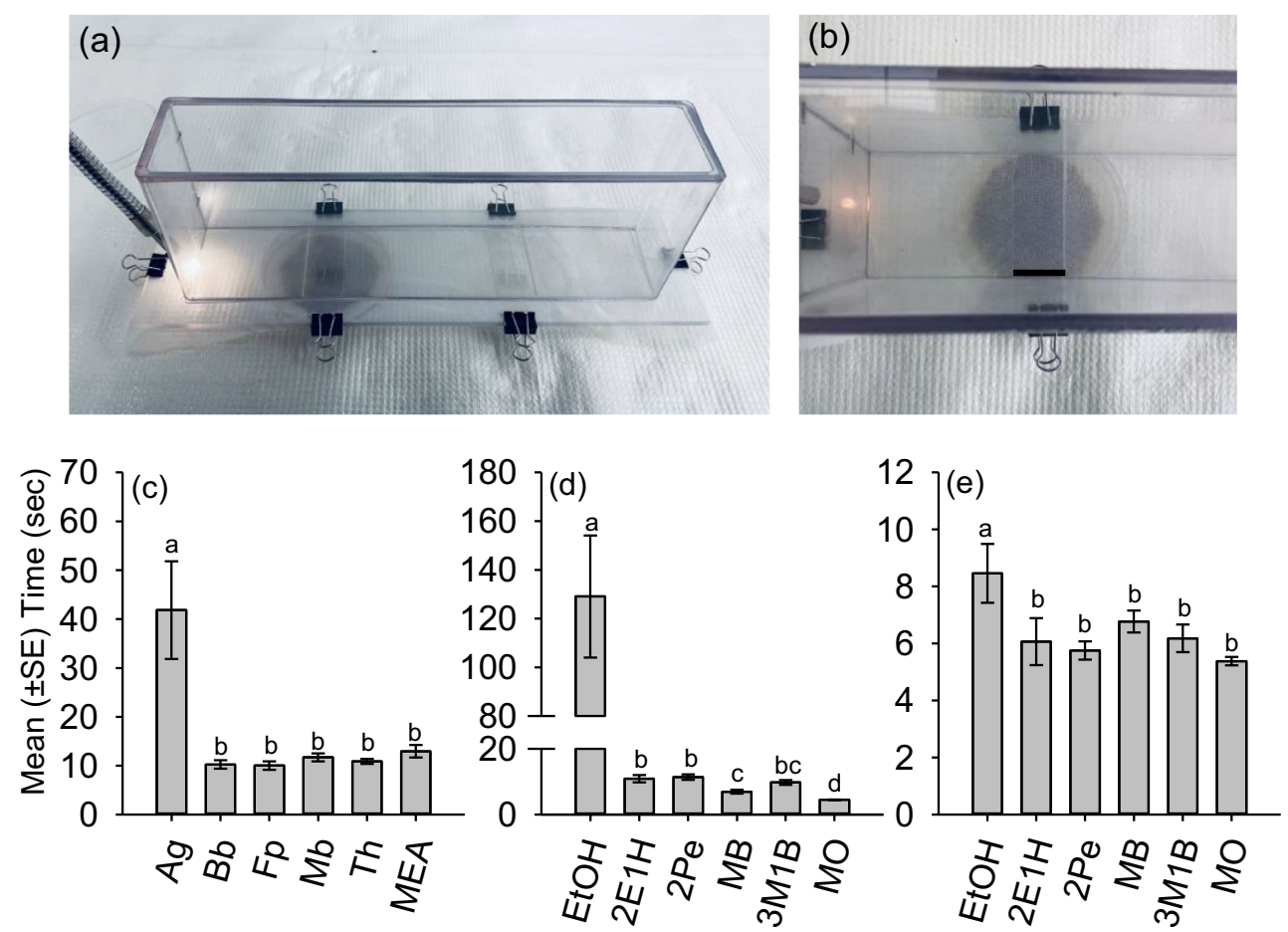

Fig. 1 a-e. a, b Still-air walking olfactometer used to measure the arrestment response of female $X$. germanus to volatile stimuli. As beetles walked along the platform towards the light source, the duration of time was measured that beetles spent within the confines of the mesh-covered rectangular opening above the petri-dish on the left side (indicated by black horizontal bar in $1 \mathrm{~B}, 2.5 \mathrm{~cm}$ ). c Duration of time that $X$. germanus spent above petri dishes containing cultures of $X$. germanus' nutritional fungal symbiont Ambrosiella grosmanniae, $\mathrm{Ag}$; entomopathogenic fungi Beauveria bassiana, $\mathrm{Bb}$, and Metarhizium brunneum, Mb; mycoparasitic fungus Trichoderma harzianum, Th; fungal plant pathogen Fusarium proliferatum, $\mathrm{Fp}$; and malt extract agar, MEA. Duration of time that $X$. germanus spent above petri dishes containing filter paper treated with $40 \mu \mathrm{l}$ of $\mathbf{d} 1 \mathrm{mg} / \mathrm{ml}$ and e $0.1 \mathrm{mg} / \mathrm{ml}$ dilutions of ethanol, EtOH; 2-ethyl-1-hexanol, 2E1H; 2-phenylethanol, 2PE; methyl benzoate, MB; 3-methyl-1-butanol, 3M1B; and mineral oil, MO. Different letters within a graph represent significantly different means using generalized linear models and least square means $((\mathbf{c})$ : $\chi^{2}=100.70 ; \mathrm{df}=5 ; P<0.0001 ;(\mathbf{d}): \chi^{2}=249.64 ; \mathrm{df}=5 ; P<0.0001 ;$ (e): $\left.\chi^{2}=17.28 ; \mathrm{df}=5 ; P=0.004\right)$ 
petri dish on the left-hand side of the observer contained a clean MEA plate or a culture of A. grosmanniae, B. bassiana, $M$. brunneum, T. harzianum, or $F$. proliferatum. Cultures were established on the MEA plates and maintained at $20^{\circ} \mathrm{C}$ for about $14 \mathrm{~d}$ before use in the bioassays. Following SPME-GC-MS analyses, additional bioassays were conducted to assess the arrestment response of $X$. germanus to the following individual compounds: ethanol, 2-ethyl-1-hexanol, 2-phenylethanol, methyl benzoate, 3-methyl-1-butanol, and a mineral oil control. A strip of filter paper $(4 \times 1 \mathrm{~cm} ; \mathrm{L} \times \mathrm{W})$ was treated with $40 \mu \mathrm{l}$ of 0.1 or $1 \mathrm{mg} / \mathrm{ml}$ dilutions in mineral oil of the aforementioned compounds to deliver $4 \mu \mathrm{g}$ and $40 \mu \mathrm{g}$, respectively. After saturation, the filter paper strip was placed in the center of the petri dish underneath the left-hand threshold of the walking platform.

A plexiglass chamber $(30 \times 6 \times 10.5 \mathrm{~cm} ; \mathrm{L} \times \mathrm{W} \times \mathrm{H})$ enclosed on all sides except for the underside was then rested on top of the platform to confine beetles during the walking bioassays. The chamber was removed to place a beetle on the walking platform and then promptly returned. Since recentlyemerged ambrosia beetles exhibit a positive phototaxic response (Borden et al. 1968; Ranger pers. obs.), a single gooseneck illuminator ( $150 \mathrm{~W}$ halogen bulb; $1500 \mathrm{~lm} / \mathrm{m}^{2}$ at $2.54 \mathrm{~cm}$ from end of illuminator) generally used for a stereomicroscope was positioned at the end of the walking platform on the left-most side to attract beetles during the walking bioassays. Bioassays were otherwise conducted in a completely dark room.

Assessing the behavioral response of $X$. germanus to volatiles of the aforementioned cultures or individual compounds was initiated by using forceps to place a single adult female near the end of the walking platform opposite the light source. Recently-emerged 3-4 d old laboratory-reared beetles (Castrillo et al. 2012) were held at room temperature in a laboratory exposed to natural light in a petri dish containing moistened filter paper for 3-5 d before use in bioassays. Beetles typically began walking towards the light source within $30 \mathrm{~s}$ of being transferred to the platform; beetles that did not exhibit a rapid positive phototaxic response were removed from the chamber and replaced. As beetles walked along the platform towards the light source, a handheld timer was used to record the duration of time that beetles spent within the confines of the mesh-covered rectangular opening in the platform.

Bioassays were conducted during 13:00 to 18:00 EST because $X$. germanus exhibits peak phototaxic behavioral and flight activity during these hours (Ranger, pers. obs.). Clean, fresh mesh fabric was used over the walking platform to test each culture or compound. The plexiglass platform and chamber were wiped clean with warm, unscented soapy water, dried using a paper towel, and allowed to air dry prior to testing each culture or compound. Lab-reared $X$. germanus ( $n=20$ individual beetles per culture or compound) were only used once to assess the behavioral response to A. grosmanniae, B. bassiana, M. brunneum, T. harzianum, $F$. proliferatum, and MEA, along with bioassays testing ethanol, 2-ethyl-1-hexanol, 2-phenylethanol, methyl benzoate, 3-methyl-1-butanol, and mineral oil. Individual beetles were not exposed to multiple cultures or compounds. To balance treatment presentation, at least five beetle replicates were measured on a given day using all the cultures or individual volatile compounds (except for $F$. proliferatum since it was tested after the other cultures).

Generalized linear models (PROC GENMOD; SAS Institute Inc., Cary, NC) were used to compare the duration of time $X$. germanus spent within the threshold above the petri dishes containing the various cultures or individual compounds. Due to non-normality, data were initially modeled using the $\log$ link function and a Poisson distribution. Goodness of fit for the model and overdispersion was then assessed using the scaled deviance $\left(\mathrm{G}^{2} / \mathrm{df}\right)$ parameter. When overdispersion was identified by a large departure $>1.0$ for the scaled deviance parameter, a negative binomial distribution and $\log$ link function was used to fit the model. Differences of least square means were used for pairwise comparisons on treatment effects with significant F-test values from analysis of variance $(\alpha=0.05)$.

\section{Analysis of Volatile Emissions}

Solid phase microextraction-gas chromatography-mass spectrometry was used to collect and identify volatile emissions from A. grosmanniae, B. bassiana, M. brunneum, T. harzianum, F. proliferatum, and a MEA control. Briefly, cultures were grown on MEA in glass test tubes $(20 \times$ $150 \mathrm{~mm}$ ) with a threaded black phenolic screw cap. After autoclaving the test tubes and MEA, an aliquot of $6.5 \mathrm{~mL}$ of agar was pipetted per test tube. Tubes were then placed in a test tube rack with a $20^{\circ}$ tilt to allow the media to solidify at an angle. Test tubes were inoculated about $14 \mathrm{~d}$ before using in SPME-GC-MS analyses like the behavioral bioassays.

For sampling culture volatiles by SPME, a $1 \mathrm{~mm}$ diam. Hole was pre-drilled into the screw cap of the test tube (Fig. 2a, b). An autoclaved cork borer was used to cut a circular disk $(1.3 \mathrm{~cm})$ from a blue septa silicone sheet $(3 \mathrm{~mm}$ thick; Chromatography Research Supplies Inc., Louisville, $\mathrm{KY}$ ). A needle was then used to puncture a hole through the center of the septum disk, and a piece of PTFE microbore tubing (0.81 mm I.D., 1.42 O.D.; Cole-Parmer, Vernon Hills, IL) was pulled through the hole in the septum disk (Fig. 2a). The disk with tubing in place was then inserted into the threaded test tube cap with the Teflon tubing extending out the top of the cap. The purpose of the PTFE tubing was to avoid puncturing the silicone septa and potentially contaminating the GC inlet liner during thermal desorption. Standard caps on the culture tubes were replaced with the modified and autoclaved SPME sampling caps immediately before sampling. A syringe containing a retracted SPME fiber (CAR/ PDMS; $75 \mu \mathrm{m}$ coating; Sigma-Aldrich, St. Louis, Missouri) 
Fig. 2 a-d Solid phase microextraction (SPME) sampling technique to collect volatiles emitted from mycelium of A. grosmanniae (pictured),

B. bassiana, M. brunneum,

T. harzianum, and

$F$. proliferatum. Teflon tubing and septum material were fitted through a pre-drilled hole in the cap $(\mathbf{a}, \mathbf{b})$ to introduce the syringe into the test tube for fiber exposure, thereby avoiding the possibility of contaminating the SPME syringe and GC-MS inlet liner with silicone septa
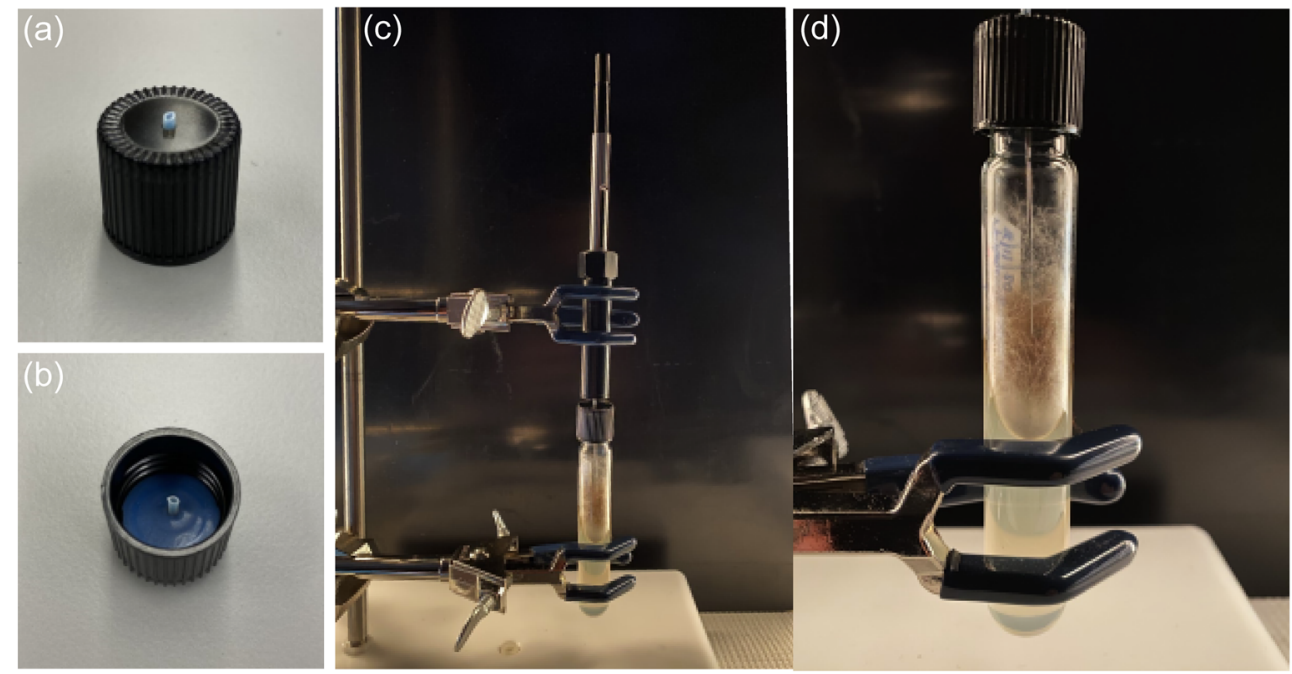

was then inserted through the test tube cap via the Teflon tubing and secured using a metal clamp and retort stand to position the end of the exposed fiber about $1 \mathrm{~cm}$ above the cultures (Fig. 2b). Four tubes with cultures incubated for about $14 \mathrm{~d}$ after inoculating were analyzed for each species, along with MEA controls. Sampling was conducted on a laboratory benchtop with an ambient temperature of $21^{\circ} \mathrm{C}$ and overhead fluorescent lighting. Fibers were exposed for $30 \mathrm{~min}$ and then immediately analyzed by GC-MS.

Fibers were thermally desorbed for $2 \mathrm{~min}$ at $225^{\circ} \mathrm{C}$ in the injection port of an Agilent 7890B GC (Agilent Technologies, Palo Alto, California) with a SPME liner $(0.75 \mathrm{~mm} \times$ $6.35 \mathrm{~mm} \times 78.5 \mathrm{~mm}$, i.d. $\times$ o.d. $\times$ length; Restek, Bellefonte, Pennsylvania) under splitless mode with 2 min splitter off time. A DB-5MS column $(0.25 \mu \mathrm{m} \times 30 \mathrm{~m} \times 0.25 \mathrm{~mm}$; i.d. $\times$ length $\times$ film thickness; cross-linked/surface bonded $5 \%$ phenyl, 95\% methylpolysiloxane; Agilent J\&W, Santa Clara, California) and a temperature program of $50-250{ }^{\circ} \mathrm{C}$ at $3{ }^{\circ} \mathrm{C} / \mathrm{min}$ were used for the analyses. An Agilent 5977A mass spectrometer was operated in electron impact mode with a scan range of 40-415 amu. Compounds that were unique to the aforementioned fungal cultures and absent in MEA volatile emissions were tentatively identified using NIST library searches. The following identifications were confirmed by comparing retention times and fragmentation patterns with authentic standards (Sigma-Aldrich): 3-methyl-1-butanol ( $\geq 99.0 \%$ chemical purity), 2-methyl-1-butanol ( $\geq 98.0 \%$ purity), 2-ethyl-1-hexanol ( $\geq 99.0 \%$ purity), methyl benzoate ( $\geq 99.5 \%$ purity), 2-phenylethanol ( $\geq 99.0 \%$ purity), 1-octen3-ol ( $\geq 98.0 \%$ purity), 2-octenal ( $\geq 95.0 \%$ purity), methyl cinnamate ( $\geq 99.0 \%$ purity), and $\alpha$-cedrene ( $\geq 95.0 \%$ purity).

\section{Olfactory Responses}

Electroantennography (EAG) was used to measure antennal olfactory responses of $5 \mathrm{~d}$ old laboratory-reared female
$X$. germanus to 2-ethyl-1-hexanol, 2-phenylethanol, methyl benzoate, 3-methyl-1-butanol, and ethanol. As described in greater detail by Ranger et al. (2014), the recording and indifferent electrodes contained Beadle-Ephrussi saline and a silver wire held in place using stainless steel electrode holders (Syntech, Buchenbach, Germany). The indifferent electrode was inserted into the foramen of a recently-excised $X$. germanus head, and the recording electrode was directed to the center of the antennal club where the majority of porous olfactory sensilla are located (Ranger et al. 2017). Micromanipulators were magnetically mounted onto the surface of an antivibration table and recordings were made within a Faraday cage (CleanBench, TMC, Peabody, MA). Antennal preparations were positioned at the end of a stainless steel odor delivery tube (diameter $0.64 \mathrm{~cm}$ ) through which humidified and carbon-filtered air passed at $150 \mathrm{~mL} / \mathrm{min}$ at approximately $2.5 \mathrm{~cm} / \mathrm{s}$.

Dilutions of 2-ethyl-1-hexanol, 2-phenethylethanol, methyl benzoate, 3-methyl-1-butanol, and ethanol ( $\geq 99.5$; SigmaAldrich) were prepared in mineral oil to achieve concentrations of $0.001,0.01,0.1$, and $1.0 \mathrm{mg} / \mathrm{mL}$. A $20 \mu \mathrm{L}$ aliquot of an individual dilution was applied to a filter paper strip $(2.5 \mathrm{~cm} \times 0.5 \mathrm{~cm}, 1 \times \mathrm{w})$ within a disposable glass Pasteur pipette. The pipette tip was inserted into a hole in the odor delivery tube about $10.8 \mathrm{~cm}$ upwind of the antennal preparation. Antennae were exposed to a 0.5 -s stimulus puff delivered by a Stimulus Controller CS 55 (Syntech) through the Pasteur pipette at $30 \mathrm{~mL} / \mathrm{min}$.

Terpinolene $(1.0 \mathrm{mg} / \mathrm{mL}$ delivered as $20 \mu \mathrm{g}$ in $20 \mu \mathrm{L}$; $>92 \%$ purity, Contech Enterprises, Inc., Victoria, BC) was used as a reference stimulus (Ranger et al. 2014). Delivery of the reference stimulus always preceded and followed stimulus puff dilutions of the aforementioned stimuli at ascending concentrations. A duration of $60 \mathrm{~s}$ was allowed to elapse between puffs. Concentration-response to each volatile stimulus was assessed using 16 separate antennal preparations. Signals 
from the recording electrode were pre-amplified by a high impedance probe (Universal Single Ended Probe, Syntech) and further amplified, filtered and optimized using a twochannel data acquisition controller (IDAC-2; Syntech). The EAG peak amplitude was measured $(\mathrm{mV})$ and then normalized relative to the response to terpinolene using the following calculation: [(response to analyte)/(initial + final response to terpinolene/2) $\times 100$. Normalizing the EAG response with a chemical standard corrects for time-dependent variability in antennal sensitivity and allows relative EAG responses to be compared with different stimuli with different cohorts of test insects (Niogret et al. 2011; Kendra et al. 2012). Generalized linear models (PROC GENMOD) with a normal distribution were used to analyze relative percent EAG responses of $X$. germanus to the four concentrations of each compound (SAS Institute Inc., Cary, NC). Comparisons were also made among the five different compounds at each of the four concentrations. Differences of least square means were used for pairwise comparisons on treatment effects $(\alpha=0.05)$.

\section{Field Behavioral Responses}

Trapping experiments were conducted under field conditions in 2016-2018 to test the attraction of $X$. germanus to 2-ethyl1-hexanol, 2-phenylethanol, methyl benzoate, 3-methyl-1-butanol, and ethanol. Bottle-traps were prepared according to Ranger et al. (2010). In short, two rectangular openings (length $12.5 \mathrm{~cm}$, width $6 \mathrm{~cm}$ ) were cut into the sides of a 1$\mathrm{L}$ plastic bottle to allow the entrance of ambrosia beetles. The 1-L bottle was inverted and the mouth was connected to a 0.5 L plastic bottle using a Tornado Tube (Steve Spangler Science, Englewood, Colorado). Lures were secured using wire within the top of the 1-L bottle and the $0.5-\mathrm{L}$ bottle was partially filled with $20 \mathrm{~mL}$ of ethanol-free propylene glycol antifreeze (PEAK® SIERRA®; Old World Industries, LLC, Northbrook, IL) as a killing and preserving agent.

Two field trapping experiments were conducted per year in 2016-2018. The first field experiment in 2016 consisted of traps being baited singly with heat-sealed pouch-style emitters of the following compounds: 2-ethyl-1-hexanol $(2.5 \mathrm{mg} / \mathrm{d}$ at $25{ }^{\circ} \mathrm{C}$; Synergy Semiochemicals, Burnaby, BC), 2phenylethanol $\left(3.0 \mathrm{mg} / \mathrm{d}\right.$ at $25^{\circ} \mathrm{C}$; Synergy), methyl benzoate diluted to $20 \%$ with acetyl tributyl citrate to slow the release rate $\left(10 \mathrm{mg} / \mathrm{d}\right.$ at $25^{\circ} \mathrm{C}$; Synergy), 3-methyl-1-butanol ( $4.5 \mathrm{mg} /$ d at $25^{\circ} \mathrm{C}$; Synergy), and ethanol $\left(16 \mathrm{mg} / \mathrm{d}\right.$ at $30^{\circ} \mathrm{C}$; AgBio Inc., Westminster, $\mathrm{CO}$ ), or non-baited. The traps were positioned $0.6 \mathrm{~m}$ above ground level by attaching the inverted end of the 1-L bottle to a metal rod staked in the ground. Traps were arranged in parallel lines in a randomized complete block design with five complete blocks within a deciduous woodlot at the Ohio Agricultural Research and Development Center, Wooster, Ohio (404' $40.46^{\prime \prime} \mathrm{N}$; 81 $\left.{ }^{\circ} 51^{\prime} 15.78^{\prime \prime} \mathrm{W}\right)$. Five $\mathrm{m}$ was maintained between adjacent traps within a block and $15 \mathrm{~m}$ between adjacent blocks. Traps were deployed from 28-June-2016 to 18-July-2016. Samples were then returned to the laboratory and identified to species level. The second field experiment conducted in 2016 consisted of an ethanol lure combined in the same trap with an individual fungal volatile lure with the aforementioned release rates. Traps were deployed as previously described and arranged in a randomized complete block design with five complete blocks from 18-July-2016 to 8-August-2016 ( $n=5$ traps per treatment). Traps baited singly were re-tested from 12-April-2017 to 3May-2017, and combined with an ethanol lure from 3-May2017 to 31-May-2017, using the aforementioned release rates and methods for 2016.

Two additional field trapping experiments were conducted in 2018 using the same randomized complete block design used in 2016-2017 but with the following reduced release rates: 2-ethyl-1-hexanol (0.6 mg/d; Synergy), 2phenylethanol $(0.8 \mathrm{mg} / \mathrm{d}$; Synergy), methyl benzoate diluted to $20 \%$ with acetyl tributyl citrate $(2.5 \mathrm{mg} / \mathrm{d}$; Synergy $)$, and 3methyl-1-butanol $(1.0 \mathrm{mg} / \mathrm{d}$; Synergy). Lures were tested singly from 16-May-2018 to 29-May-2018 and combined with ethanol from 29-May-2018 to 26-June-2018.

A generalized linear model (PROC GENMOD) was used to analyze trap count data of $X$. germanus (SAS Institute Inc., Cary, NC). Due to non-normality, data were initially modeled assuming a Poisson distribution with a goodness of fit for the model being assessed using the scaled deviance $\left(\mathrm{G}^{2} / \mathrm{df}\right)$ parameter. When overdispersion was detected by a large departure from 1.0 for the scaled deviance parameter, a negative binomial distribution and log link function was used to fit the model. Differences of least square means were used for pairwise comparisons on treatment effects with significant Ftest values from analysis of variance $(\alpha=0.05)$.

\section{Results}

\section{Behavioral Bioassay}

During still-air walking bioassays, $X$. germanus exhibited a stronger arrestant response to volatiles of its fungal symbiont A. grosmanniae compared to the entomopathogenic fungi $B$. bassiana and $M$. brunneum, the mycoparasitic fungus $T$. harzianum, the plant pathogen $F$. proliferatum, and a MEA control (Fig. 1c). As $X$. germanus oriented along a walking platform towards a light source (Fig. 1a, b), individual beetles spent a significantly longer duration arrested over a culture of A. grosmanniae compared to B. bassiana, $M$. brunneum, T. harzianum, F. proliferatum, and a MEA control (Fig. 1c). No difference was detected in the duration of time $X$. germanus spent positioned over the non-symbiont cultures or the MEA control. 
Based on SPME-GC-MS analyses, subsequent walking bioassays were conducted to assess the behavioral response of $X$. germanus to 2-ethyl-1-hexanol, 2-phenylethanol, methyl benzoate, and 3-methyl-1-butanol (Fig. 1d-e). When tested singly, $X$. germanus spent a significantly longer duration of time above a strip of filter paper treated with $40 \mu \mathrm{l}$ of $1 \mathrm{mg} / \mathrm{ml}$ (i.e. $40 \mu \mathrm{g}$ ) or $0.1 \mathrm{mg} / \mathrm{ml}$ (i.e. $4 \mu \mathrm{g}$ ) of ethanol compared to the remaining compounds or mineral oil (Fig. 1d-e). At $40 \mu \mathrm{g}$, $X$. germanus spent a longer duration of time over filter paper treated with 2-ethyl-1-hexanol and 2-phenylethanol compared to methyl benzoate; the shortest duration of time was spent over filter paper treated with mineral oil (Fig. 1d). At $4 \mu \mathrm{g}$, there was no difference in the duration of time $X$. germanus spent over filter paper treated with 2-ethyl-1-hexanol, 2phenylethanol, methyl benzoate, 3-methyl-1-butanol or mineral oil (Fig. 1e).

\section{Analysis of Volatile Emissions}

SPME-GC-MS analysis identified four compounds present in volatile emissions from A. grosmanniae growing on MEA, including three alcohols (i.e., 3-methyl-1-butanol, 2phenylethanol, and 2-ethyl-1-hexanol) and one ester (i.e., methyl benzoate) (Table 1). These compounds were not detected in the MEA controls.

Seven compounds were detected by SPME-GC-MS in emissions from the entomopathogenic fungus $B$. bassiana growing on MEA, including three alcohols (i.e., 2-methyl-1butanol, 3-methyl-1-butanol,1-octen-3-ol), one aldehydehyde (i.e., 2-octenal), two esters (i.e., methyl benzoate, methyl cinnamate), and a tentatively identified sesquiterpene (i.e., $\beta$-elemene) (Table 1). SPME-GC-MS detected nine compounds in emissions from the mycoparasitic fungus T. harzianum growing on MEA, including one alcohol (i.e., 1-octen-3-ol) and eight tentatively identified sesquiterpenes (Table 1). No unique volatiles were detected in emissions of the entomopathogenic fungus $M$. brunneum as compared to the MEA control. Five tentatively identified sesquiterpenes were detected in emissions from $F$. proliferatum (Table 1).

A comparison of volatile emissions determined that two compounds were detected in emissions from A. grosmanniae and B. bassiana, namely, 3-methyl-1butanol and methyl benzoate. Two of the tentatively identified sesquiterpenes were shared between volatile emissions of $T$. harzianum and $F$. proliferatum, namely, $\alpha$-acoradiene and $\beta$-cedrene.

\section{Electroantennogram Responses}

Olfactory responses of $X$. germanus were measured using EAG in response to ascending concentrations of 2-ethyl-1-hexanol, 2phenylethanol, methyl benzoate, 3-methyl-1-butanol, and ethanol (Fig. 3a-e). After normalizing the absolute responses relative
Table 1 SPME-GC-MS analysis of volatiles associated with the ambrosia beetle nutritional fungal symbiont Ambrosiella grosmanniae (A.g.), entomopathogenic fungus Beauveria bassiana (B.b.), mycoparasitic fungus Trichoderma harzianum (T.h.), and the fungal plant pathogen Fusarium proliferatum (F.p.)

\begin{tabular}{|c|c|c|c|c|}
\hline \multirow{2}{*}{$\begin{array}{l}\text { Species } \\
\text { A.g. }\end{array}$} & \multirow{2}{*}{$\begin{array}{l}\text { Compound }^{\mathrm{a}} \\
\text { 3-Methyl-1-Butanol }\end{array}$} & \multirow{2}{*}{$\begin{array}{l}\text { Formula } \\
\mathrm{C}_{5} \mathrm{H}_{12} \mathrm{O}\end{array}$} & \multicolumn{2}{|c|}{$\begin{array}{l}\text { Mean }( \pm \text { SE) } \\
\text { Composition }(\%)\end{array}$} \\
\hline & & & 93.17 & \pm 0.51 \\
\hline & 2-Ethyl-1-Hexanol ${ }^{\ddagger}$ & $\mathrm{C}_{8} \mathrm{H}_{18} \mathrm{O}$ & 3.21 & \pm 0.25 \\
\hline & Methyl Benzoate ${ }^{\ddagger}$ & $\mathrm{C}_{8} \mathrm{H}_{8} \mathrm{O}_{2}$ & 1.90 & \pm 0.20 \\
\hline & 2-Phenylethanol ${ }^{\ddagger}$ & $\mathrm{C}_{8} \mathrm{H}_{10} \mathrm{O}$ & 1.72 & \pm 0.11 \\
\hline \multirow[t]{7}{*}{ B.b. } & 3-Methyl-1-Butanol & $\mathrm{C}_{5} \mathrm{H}_{12} \mathrm{O}$ & 13.26 & \pm 4.92 \\
\hline & 2-Methyl-1-Butanol ${ }^{\ddagger}$ & $\mathrm{C}_{5} \mathrm{H}_{12} \mathrm{O}$ & 27.44 & \pm 7.65 \\
\hline & 1-Octen-3-ol & $\mathrm{C}_{8} \mathrm{H}_{16} \mathrm{O}$ & 19.26 & \pm 1.64 \\
\hline & 2-Octenal ${ }^{*}$ & $\mathrm{C}_{8} \mathrm{H}_{14} \mathrm{O}$ & 12.27 & \pm 7.53 \\
\hline & Methyl Benzoate & $\mathrm{C}_{8} \mathrm{H}_{8} \mathrm{O}_{2}$ & 5.97 & \pm 1.83 \\
\hline & Methyl Cinnamate & $\mathrm{C}_{10} \mathrm{H}_{10} \mathrm{O}_{2}$ & 10.62 & \pm 0.84 \\
\hline & $\beta$-Elemene ${ }^{\dagger}$ & $\mathrm{C}_{15} \mathrm{H}_{24}$ & 11.18 & \pm 3.55 \\
\hline \multirow[t]{5}{*}{ F.p. } & Acoradiene-derivative $^{\dagger}$ & $\mathrm{C}_{15} \mathrm{H}_{24}$ & 5.20 & \pm 1.30 \\
\hline & $\alpha$-Cedrene & $\mathrm{C}_{15} \mathrm{H}_{24}$ & 12.53 & \pm 3.45 \\
\hline & $\beta$-Cedrene ${ }^{\dagger}$ & $\mathrm{C}_{15} \mathrm{H}_{24}$ & 9.53 & \pm 0.18 \\
\hline & Muurolene-derivative $^{\dagger}$ & $\mathrm{C}_{15} \mathrm{H}_{24}$ & 2.48 & \pm 1.03 \\
\hline & $\alpha$-Acoradiene ${ }^{\dagger}$ & $\mathrm{C}_{15} \mathrm{H}_{24}$ & 70.26 & \pm 1.67 \\
\hline \multirow[t]{9}{*}{ T.h. } & 1-Octen-3-ol ${ }^{*}$ & $\mathrm{C}_{8} \mathrm{H}_{16} \mathrm{O}$ & 3.56 & \pm 1.08 \\
\hline & $\alpha$-Copaene ${ }^{\dagger}$ & $\mathrm{C}_{15} \mathrm{H}_{24}$ & 21.10 & \pm 1.37 \\
\hline & $\beta$-Cedrene ${ }^{\dagger}$ & $\mathrm{C}_{15} \mathrm{H}_{24}$ & 32.82 & \pm 1.33 \\
\hline & $\gamma$-Muurolene ${ }^{\dagger}$ & $\mathrm{C}_{15} \mathrm{H}_{24}$ & 12.32 & \pm 0.65 \\
\hline & $(+)$-Sativene ${ }^{\dagger}$ & $\mathrm{C}_{15} \mathrm{H}_{24}$ & 2.05 & \pm 0.08 \\
\hline & $\alpha$-Acoradiene ${ }^{\dagger}$ & $\mathrm{C}_{15} \mathrm{H}_{24}$ & 5.18 & \pm 0.31 \\
\hline & $\gamma$-Acoradiene ${ }^{\dagger}$ & $\mathrm{C}_{15} \mathrm{H}_{24}$ & 3.99 & \pm 0.24 \\
\hline & Acorenone-derivative ${ }^{\dagger}$ & $\mathrm{C}_{15} \mathrm{H}_{26} \mathrm{O}$ & 10.42 & \pm 1.42 \\
\hline & Acorenone $^{\dagger}$ & $\mathrm{C}_{15} \mathrm{H}_{24} \mathrm{O}$ & 8.58 & \pm 3.90 \\
\hline
\end{tabular}

${ }^{\text {a }}$ Identifications based on comparing mass spectra in the National Institute of Standards and Technology (NIST) library ( $\dagger$ ), or comparing with NIST and an authentic standard $(\$)$

to terpinolene, a positive concentration response was documented for ethanol such that $20 \mu \mathrm{g}$ in $20 \mu \mathrm{l}$ elicited a significantly larger antennal depolarization response than 0.02 and $0.2 \mu \mathrm{g}$ in $20 \mu \mathrm{l}$ (Fig. 3a). A positive concentration response was also documented for methyl benzoate, such that $2 \mu \mathrm{g}$ and $20 \mu \mathrm{g}$ in $20 \mu \mathrm{l}$ elicited significantly larger antennal responses than $0.02 \mu \mathrm{g}$ in $20 \mu \mathrm{l}$ (Fig. 3d). A positive antennal concentration response was not observed for 2-ethyl-1-hexanol, 2-phenylethanol, or 3methyl-1-butanol ranging at concentrations ranging from 0.02 $20 \mu \mathrm{g}$ in $20 \mu \mathrm{l}$ (Fig. 3b, c, e).

When compared among the five volatile compounds, ethanol at $2 \mu \mathrm{g}$ and $20 \mu \mathrm{g}$ in $20 \mu \mathrm{l}$ elicited significantly larger depolarizations than the remaining compounds at these corresponding concentrations (Fig. 3a). There was no difference in depolarizations for 2-ethyl-1-hexanol, 2-phenylethanol, 


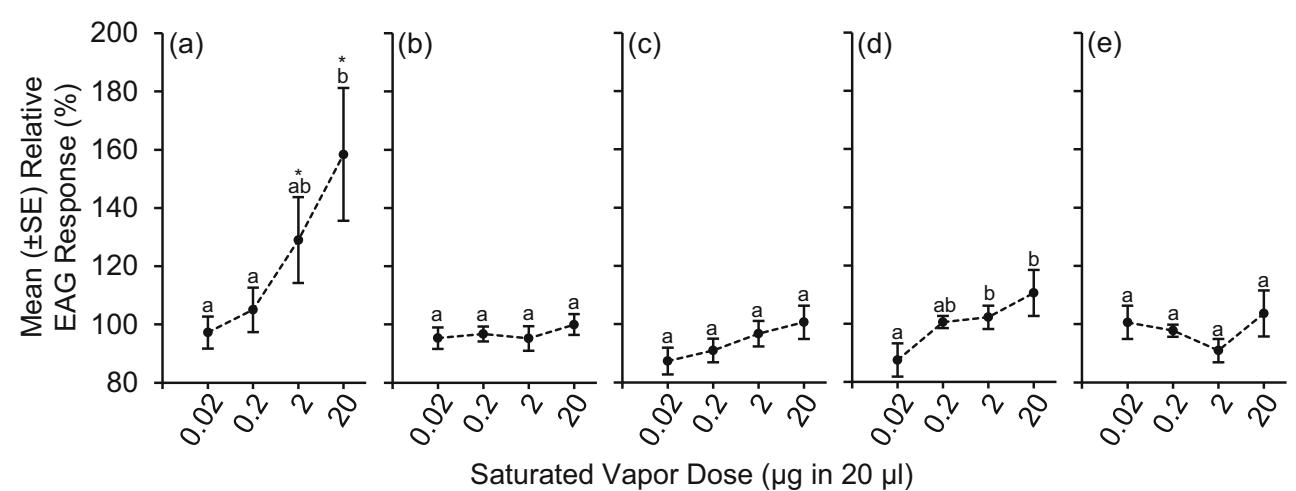

Fig. 3 a-e. Relative EAG responses of $X$. germanus to serial dilutions of ethanol, EtOH; 2-ethyl-1-hexanol, 2E1H; 2-phenylethanol, 2Pe; methyl benzoate, MB; 3-methyl-1-butanol, 3 MB; and ethanol, EtOH. Relative responses were calculated by normalizing the absolute EAG peak amplitudes relative to the response to saturated vapor concentration of terpinolene $(20 \mu \mathrm{g}$ in $20 \mu \mathrm{l})$. Different letters within a graph represent significantly different means using generalized linear models and least

methyl benzoate, and 3-methyl-1-butanol when tested at concentrations ranging from $0.02-20 \mu \mathrm{g}$ in $20 \mu \mathrm{l}$.

\section{Field Behavioral Responses}

When the fungal volatiles were tested singly at the higher release rate in 2016, significantly more $X$. germanus were attracted to traps baited with ethanol, 2-ethyl-1-hexanol, 2phenylethanol, methyl benzoate, or 3-methyl-1-butanol compared to the blank control (Fig. 4a). Ethanol alone attracted the most $X$. germanus, while 2-ethyl-1-hexanol and methyl benzoate attracted more $X$. germanus than 2-phenyethanol and 3methyl-1-butanol (Fig. 4a). When re-tested singly in 2017, there was no difference in the number of $X$. germanus attracted to traps baited with 2-ethyl-1-hexanol, 2phenylethanol, methyl benzoate, 3-methyl-1-butanol, or the blank control (Fig. 4c). Traps baited with ethanol alone attracted significantly more $X$. germanus than all other compounds.

When paired with ethanol and tested in 2016, traps baited with ethanol plus methyl benzoate attracted a comparable number of $X$. germanus compared to traps baited with ethanol alone (Fig. 4b). In contrast, traps baited with ethanol plus 2ethyl-1-hexanol, ethanol plus 2-phenylethanol, and ethanol plus 3-methyl-1-butanol attracted fewer $X$. germanus than traps baited with ethanol alone. When re-tested in 2017, traps baited with ethanol plus 2-ethyl-1-hexanol and ethanol plus methyl benzoate attracted a comparable number of $X$. germanus compared to traps baited with ethanol alone (Fig. 4d). In contrast, traps baited with ethanol plus 2phenylethanol and ethanol plus 3-methyl-1-butanol attracted significantly fewer $X$. germanus than ethanol alone.

In 2018 with reduced rates of the fungal volatiles, there was no difference in the attraction of $X$. germanus to each of the four fungal volatiles tested singly compared to the non-baited square means $\left((\mathbf{a}): \chi^{2}=11.40 ; \mathrm{df}=3 ; P=0.01 ;(\mathbf{b}): \chi^{2}=1.23 ; \mathrm{df}=3 ; P=\right.$ $0.75 ;(\mathbf{c}): \chi^{2}=4.83 ; \mathrm{df}=3 ; P=0.18 ;(\mathbf{d}): \chi^{2}=9.33 ; \mathrm{df}=3 ; P=0.03 ;(\mathbf{e})$ : $\chi^{2}=7.32 ; \mathrm{df}=3 ; P=0.06$ ). Asterisks within (a) represent a significant difference between saturated concentration of ethanol at $2 \mu \mathrm{g}$ in $20 \mu \mathrm{l}$ $\left(\chi^{2}=15.80 ; \mathrm{df}=4 ; P=0.0033\right)$ and $20 \mu \mathrm{g}$ in $20 \mu \mathrm{l}\left(\chi^{2}=18.27 ; \mathrm{df}=4\right.$; $P=0.0011)$ compared to the four other fungal volatiles at these concentrations

blank control (Fig. 4e). When combined with an ethanol lure and tested in 2018, there was no difference in the attraction of $X$. germanus to traps baited with ethanol plus 2-ethyl-1hexanol and ethanol plus methyl benzoate compared to ethanol alone, whereas 2-phenylethanol and 3-methyl-1-butanol still reduced the attraction of $X$. germanus to ethanol at the lower release rate tested in 2018 (Fig. 4f).

\section{Discussion}

The role of fungal volatiles in mediating interactions among fungi and insect symbionts is receiving increased attention, but has been largely unexplored, especially for bark and ambrosia beetles associated with symbiotic fungi (Cale et al. 2016). As part of our current study, X. germanus exhibited a short-range arrestment response to fungal volatiles emitted by the mycelium of its nutritional fungal symbiont, but not to emissions from two entomopathogenic fungi, a mycoparasitic fungus, or a fungal pathogen. SPME-GC-MS identified four volatile compounds in the emissions of $A$. grosmanniae growing on MEA, namely, 2-ethyl-1-hexanol, 2-phenylethanol, methyl benzoate, and 3-methyl-1-butanol. Compared to ethanol, relatively weak antennal depolarizations were exhibited by $X$. germanus to these four fungal volatiles. Weak or no response to the individual volatiles was also documented during walking bioassays and field trials. None of the fungal volatiles enhanced attraction of $X$. germanus to ethanol when tested singly in field trials; in contrast, 2-phenylethanol and 3methyl-1-butanol consistently reduced attraction to ethanol. Volatiles emitted by A. grosmanniae may function as shortrange olfactory cues that aid in distinguishing their nutritional fungal symbiont from other fungi, but these compounds do not function as long-range attractants. For instance, olfactory and behavioral responses of $X$. germanus to these compounds 
Fig. 4 a-f. Captures of $X$. germanus in traps deployed in a, b 2016, c, d 2017, and e, f 2018 that were baited singly $\mathbf{a}, \mathbf{c}, \mathbf{e}$ or paired with ethanol $\mathbf{b}, \mathbf{d}, \mathbf{f}$ to test the attractiveness of ethanol, EOH; 2-ethyl-1-hexanol, 2E1H; 2-phenylethanol, 2Pe; methyl benzoate, MB; 3-methyl-1butanol, $3 \mathrm{MB}$. The following release rates were tested in 2016 2017: 2-ethyl-1-hexanol (2.5 mg/ d), 2-phenylethanol $(3.0 \mathrm{mg} / \mathrm{d})$, methyl benzoate $(10.0 \mathrm{mg} / \mathrm{d})$, and 3-methyl-1-butanol (4.5 mg/d). The following release rates were tested in 2018: 2-ethyl-1-hexanol $(0.6 \mathrm{mg} / \mathrm{d}), 2$-phenylethanol $(0.8 \mathrm{mg} / \mathrm{d})$, methyl benzoate (2.5 mg/d), and 3-methyl-1butanol $(1.0 \mathrm{mg} / \mathrm{d})$. Different letters within a graph represent significantly different means using generalized linear models and least square means $\left((\mathbf{a}): \chi^{2}=\right.$ $80.83 ; \mathrm{df}=5 ; P<0.0001 ;(\mathbf{b})$ : $\chi^{2}=36.57 ; \mathrm{df}=5 ; P<0.0001$ (c): $\chi^{2}=75.98 ; \mathrm{df}=5$;

$P<0.0001 ;(\mathbf{d}): \chi^{2}=597.16 ; \mathrm{df}=$

5; $P<0.0001 ;(\mathbf{e}): \chi^{2}=48.93$;

$\mathrm{df}=5 ; P<0.0001 ;(\mathbf{f}): \chi^{2}=$

$79.21 ; \mathrm{df}=5 ; P<0.0001)$
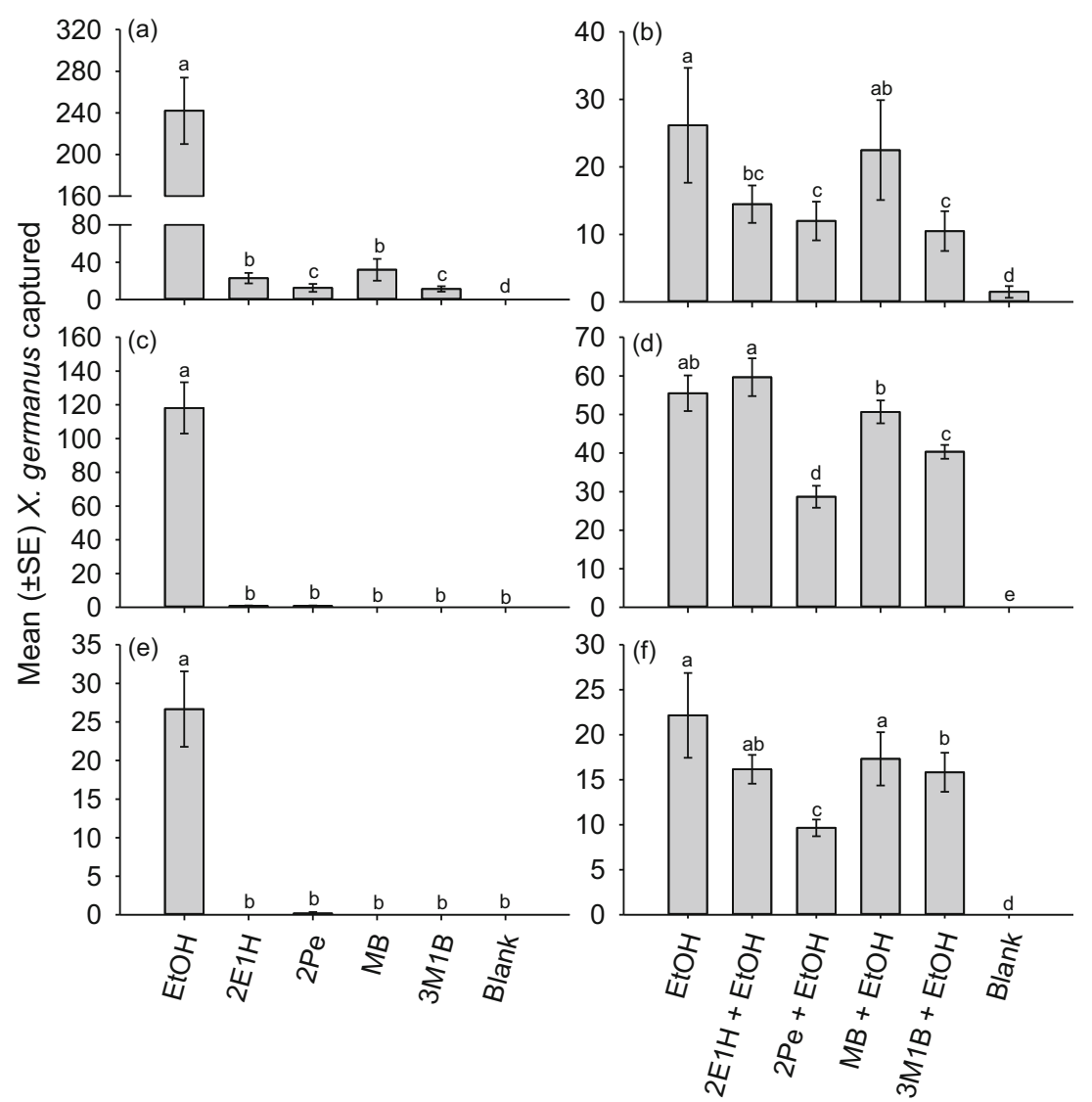

could be a function of A. grosmanniae being their sole source of nutrition, thereby critical semiochemicals linked to their survival and fitness perhaps by helping to maintain the specific symbiosis between $X$. germanus and A. grosmanniae. These responses could also be related to the association of these compounds with host trees (Holighaus and Schütz 2006), or represent compounds often found in the beetles environment (i.e., semiochemical parsimony) as described by Blum (1996). Similarly, the 'neutral hypothesis' proposes that microbial volatile emissions might influence insect behavior by coincidence, potentially due to similarity with evolutionarily relevant infochemicals (Davis et al. 2013).

Our current study supports a small body of work demonstrating that ambrosia beetles respond to the volatile profile of their fungal symbiont and can perhaps distinguish it from other fungal volatile profiles. Xylosandrus compactus displayed short-range attraction to its fungal symbiont ( $F$. solani) during olfactometer bioassays, but comparisons were only made against an agar control (Egonyu and Torto 2018). Similarly, Hulcr et al. (2011) demonstrated that three species of ambrosia beetles exhibited short-range attraction exclusively to fungal volatiles emitted from their symbionts, including Ambrosiella xylebori, Ambrosiozyma sp., and Raffaelea lauricola, but were non-responsive or repelled by Trichoderma sp. (Hulcr et al. 2011). However, a limitation of the study by Hulcr et al. (2011) is that a non-pathogenic, non- symbiotic fungal species was not tested. Unlike the response to A. grosmanniae, $X$. germanus did not exhibit an arrestment response to volatiles associated with the entomopathogenic fungi B. bassiana and M. brunneum, the mycoparasitic fungus $T$. harzianum, or the plant pathogen $F$. proliferatum as a representative of a non-pathogenic, non-symbiotic fungus. Additional free-choice studies are warranted to assess what volatiles influence the short-range behavioral response of $X$. germanus to its fungal symbiont. In addition, our SPMEGC-MS analyses tentatively identified a variety of sesquiterpenes from $T$. harzianum that could have repellent activity in support of bioassays by Hulcr et al. (2011).

Ethanol, 2-methyl-1-propanol, and 3-methyl-1-butanol were detected by SPME-GC-MS from an unspecified Ambrosiella sp., and ethanol, ethyl acetate, 2-methyl-1propanol, 3-methyl-1-butanol, and 3-methyl-1-butanol acetate were emitted from $R$. lauricola, the symbiont of $X$. glabratus (Kuhns et al. 2014). SPME-GC-MS analysis of volatile emissions from $F$. solani, the symbiont of $X$. compactus, identified ethanol, 3-methyl-1-butanol, and (E)- $\beta$-caryophyllene as predominant (Egonyu and Torto 2018). We detected 2-ethyl-1hexanol, 2-phenylethanol, methyl benzoate, and 3-methyl-1butanol by SPME-GC-MS from A. grosmanniae growing on MEA. SPME can be superior to dynamic headspace sampling for minimizing the loss or obscuration of highly volatile compounds, but vacuum-assisted sampling as part of the latter 
technique is useful for collecting volatile and semi-volatile compounds (D'Alessandro and Turlings 2006; Jeleń 2003; Morath et al. 2012). For instance, Egonyu and Torto (2018) detected 40 compounds emitted by $F$. solani using dynamic headspace sampling compared to 9 compounds detected by SPME. 3-Methyl-1-butanol was a predominant compound collected using SPME and dynamic headspace sampling from F. solani (Egonyu and Torto 2018). Similarly, 3-methyl-1butanol was a predominant volatile collected by dynamic headspace sampling, along with eight other compounds, from fungal symbionts of the mountain pine beetle (Dendroctonus ponderosae Hopkins) (Cale et al. 2016).

Some of the volatiles identified from ambrosia beetle fungal symbionts appear to be ubiquitous, especially 3-methyl-1butanol (Cale et al. 2016; Egonyu and Torto 2018; Korpi et al. 2009; Kuhns et al. 2014; Morath et al. 2012). Our results suggest $A$. grosmanniae is associated with a relatively simple volatile profile but could have a characteristic odor as documented for other fungi (Morath et al. 2012). Furthermore, volatile blends likely represent more distinguishing information than the presence of individual compounds. Percent compositions associated with SPME analyses in our current study and previous ones (Kuhns et al. 2014) must also be considered qualitatively since calibrations for specific volatile compounds were not performed. Thus, the abundance and ratio of volatiles emitted from A. grosmanniae could be quite different from the SPME analyses. As noted by Jelen (2003), peak areas of individual compounds extracted by SPME can be influenced by a variety of factors, including fiber coatings, temperature, time, $\mathrm{pH}$, and others. The intention of our current study was to establish a qualitative volatile profile of A. grosmanniae in pursuit of behaviorally active compounds rather than quantitatively characterize volatile emissions of this fungal symbiont.

Notably, 3-methyl-1-butanol and methyl benzoate were detected in emissions from A. grosmanniae and B. bassiana, but $X$. germanus did not exhibit an arrestment response to this entomopathogenic fungus during our bioassays. Quantitative analyses of volatile emissions from A. grosmanniae and $B$. bassiana would be useful for comparing major, minor, and trace components between these two species. Crespo et al. (2008) detected ethanol, sesquiterpenes, and diisopropyl naphthalenes, while Bojke et al. (2018) detected 3-methylbutanal, fatty acids, and sesquiterpenes by SPMEGC-MS in volatile emissions from $B$. bassiana.

As previously noted, ethanol was detected in emissions from ambrosia beetle fungal symbionts (Egonyu and Torto 2018; Kuhns et al. 2014). We did not detect the emission of ethanol from A. grosmanniae at 14 days after inoculating the MEA as part of our current study, but subsequent analyses have detected the emission of ethanol from A. grosmanniae at $5 \mathrm{~d}$ after inoculating MEA media (Ranger, pers. obs.). The emission of ethanol from vulnerable host trees (Ranger et al.
2021) and by ambrosia beetle fungal symbionts (Egonyu and Torto 2018; Kuhns et al. 2014) could account for the strong behavioral response exhibited by $X$. germanus and other ambrosia beetle to this semiochemical. Since ethanol promotes the growth of Ambrosiella spp. and inhibits the growth of fungal garden competitors (Ranger et al. 2018), its emission by Ambrosiella spp. might also serve in a defensive capacity to suppress the establishment of antagonists. As the profile of volatiles emitted by fungi can vary depending on substrate, duration of incubation, nutrients, temperature, and other parameters (Morath et al. 2012), additional time-course studies are warranted to further characterize fungal volatiles emitted by $A$. grosmanniae. In particular, volatile profiles should be compared for symbionts growing on MEA alone vs. MEA infused with sawdust from host trees, along with cultures within host tree galleries.

Unlike the concentration-response to ethanol, relatively weak EAG concentration-responses were elicited by 2-ethyl1-hexanol, 2-phenylethanol, methyl benzoate, and 3-methyl1-butanol as part of our current study. Due to the close evolutionary and ecological association between ambrosia beetles and their fungal symbionts, the olfactory system of ambrosia beetles could contain narrowly tuned, highly specific olfactory receptors that are wired to dedicated neuronal circuits in response to these ecologically relevant odors (Andersson et al. 2015). Data from our current study does not support this scenario for 2-ethyl-1-hexanol, 2-phenylethanol, methyl benzoate, or 3-methyl-1-butanol, but a narrowly tuned receptor that is highly specific to ethanol could be associated with $X$. germanus. Single sensillum recordings from the antennal club of $X$. germanus would help to characterize the specificity of the different sensilla types, particularly for ethanol (Andersson et al. 2015; Olsson and Hansson 2013).

As compared to ethanol, some arrestment responses were exhibited by $X$. germanus to the individual fungal volatiles tested during the still-air olfactometer bioassays. Still, these results demonstrate the walking bioassay first described by Borden et al. (1968) is useful for measuring the behavioral response of ambrosia beetles. Weak and inconsistent longrange attraction was exhibited by $X$. germanus to the individual fungal volatiles when tested in 2016-2018. None of the compounds enhanced attraction to ethanol, and 2phenylethanol and 3-methyl-1-butanol consistently reduced attraction to ethanol. 2-Phenylethanol inhibited the response of Dendroctonus frontalis Zimmermann and Dendroctonus ponderosae Hopkins to attractants (Pureswaran et al. 2000; Sullivan et al. 2007) but enhanced the attraction of Ips paraconfusus Lanier to male-infested logs (Renwick et al. 1976). The basis for inhibition could be related to the variety of origins of 2-phenylethanol, including bark beetles and associated microorganisms (Sullivan 2005; Sullivan et al. 2007). Similarly, X. compactus exhibited antennal responses to meth$\mathrm{yl}$ isovalerate and 2,3-butanediol in adsorbent-trapped extracts 
from $F$. solani during gas chromatographyelectroantennography experiments (Egonyu and Torto 2018), but unlike ethanol these compounds were only slightly attractive when tested singly under field conditions.

While semiochemical release rate is critical, Davis et al. (2013) noted that a central question of insect olfactory responses to fungal volatiles is whether the insects perceive the volatiles individually or as a mixture. Individual volatiles are probably not as informative as blends (Davis et al. 2013), as demonstrated for insect responses to plant volatiles (Webster et al. 2008). Still, ethanol alone is highly attractive to ambrosia beetles and emitted from both their host trees (Ranger et al. 2021) and fungal symbionts (Egonyu and Torto 2018; Kuhns et al. 2014). Subsequent studies are being pursued to test blends of volatiles based on the profile emitted from A. grosmanniae, but challenges exist with crossreactivity and release rates among compounds of varying chemical classes when pursuing an optimal lure (Nielsen et al. 2019). Notably, a synthetic blend of fungal volatiles from $R$. lauricola consisting of ethyl acetate: ethanol: isoamyl alcohol: isoamyl acetate (36.5: 29: 22: 12.5) was not alone attractive to $X$. glabratus, but did synergistically enhance attraction to a Manuka oil lure comprised of host volatiles (Kuhns et al. 2014).

Our current findings contribute to a small but growing body of research seeking to characterize how fungal volatiles mediate interactions between ambrosia beetles and their fungal symbionts. Overall, results from our current study indicate that $X$. germanus can sense general volatiles emitted from A. grosmanniae, but it is unclear if these compounds are related to symbiosis. Our results also indicate that fungal volatiles identified from A. grosmanniae are not promising semiochemicals to enhance the attraction to ethanol for monitoring or mass trapping purposes. Since ethanol represents a strong long-range attractant for $X$. germanus and many other ambrosia beetles, a more effective blend could be difficult to achieve. Still, a range of ecological and practical topics could be addressed, including further characterization of fungal volatiles and factors influencing emissions, olfactory selectivity and sensitivity by ambrosia beetles, and lure optimization.

Acknowledgements We thank the anonymous reviewers for helping to improve the quality of the manuscript. This review was supported in part by the USDA Floriculture and Nursery Research Initiative, Horticultural Research Institute, and USDA-ARS National Program 305 (Project 508221000-018-00D).

Authors' Contributions Christopher M. Ranger: Conceived and designed the research, conducted lab and field experiments, statistically analyzed the data, and wrote the manuscript. Marek Dzurenko: Conducted lab experiments. Jenny Barnett: Conducted lab experiments. Ruchika Geedi: Conducted lab experiments. Louela Castrillo: Provided fungal cultures and codesigned the research. Matthew Ethington: Conducted field experiments. Matthew Ginzel: Conducted field experiments. Karla
Addesso: Conducted field experiments. Michael E. Reding: Codesigned the research and helped to write the manuscript. All authors have read and approved the manuscript.

Declarations All the procedures performed in studies involving insects were in accordance with the ethical standards of the institution or practice at which the studies were conducted.

This article does not contain any studies with human participants or vertebrate animals performed by any of the authors.

\section{Conflict of Interest None.}

Open Access This article is licensed under a Creative Commons Attribution 4.0 International License, which permits use, sharing, adaptation, distribution and reproduction in any medium or format, as long as you give appropriate credit to the original author(s) and the source, provide a link to the Creative Commons licence, and indicate if changes were made. The images or other third party material in this article are included in the article's Creative Commons licence, unless indicated otherwise in a credit line to the material. If material is not included in the article's Creative Commons licence and your intended use is not permitted by statutory regulation or exceeds the permitted use, you will need to obtain permission directly from the copyright holder. To view a copy of this licence, visit http://creativecommons.org/licenses/by/4.0/.

\section{References}

Agnello AM, Breth DI, Tee EM, Cox KD, Villani SM, Ayer KM, Wallis AE, Donahue DJ, Combs DB, Davis AE, Neal JA (2017) Xylosandrus germanus (Coleoptera: Curculionidae: Scolytinae) occurrence, fungal associations, and management trials in New York apple orchards. J Econ Entomol 110:2149-2164

Andersson MN, Löfstedt C, Newcomb RD (2015) Insect olfaction and the evolution of receptor tuning. Front Ecol Evol 3:53

Batra LR (1985) Ambrosia beetles and their associated fungi: research trends and techniques. Proc Plant Sci 94:137-148

Biedermann PHW, Taborsky M (2011) Larval helpers and age polyethism in ambrosia beetles. PNAS 108:17064-17069

Blum MS (1996) Semiochemical parsimony in the Arthropoda. Annu Rev Entomol 41:353-374

Bojke A, Tkaczuk C, Stepnowski P, Gołębiowski M (2018) Comparison of volatile compounds released by entomopathogenic fungi. Microbiol Res 214:129-136

Borden JH, Brownlee RG, Silverstein RM (1968) Sex pheromone of Trypodendron lineatum (Coleoptera: Scolytidae): production, bioassay, and partial isolation. Can Entomol 100:629-636

Cale JA, Collignon RM, Klutsch JG, Kanekar SS, Hussain A, Erbilgin N (2016) Fungal volatiles can act as carbon sources and semiochemicals to mediate interspecific interactions among bark beetleassociated fungal symbionts. PLoS One 11:e0162197

Castrillo LA, Griggs MH, Vandenberg JD (2012) Brood production by Xylosandrus germanus (Coleoptera: Curculionidae) and growth of its fungal symbiont on artificial diet based on sawdust of different tree species. Env Entomol 41:822-827

Castrillo LA, Griggs MH, Vandenberg JD (2016) Competition between biological control fungi and fungal symbionts of ambrosia beetles Xylosandrus crassiusculus and X. germanus (Coleoptera: Curculionidae): mycelial interactions and impact on beetle brood production. Biol Control 103:138-146

Crespo R, Pedrini N, Juárez MP, Bello GMD (2008) Volatile organic compounds released by the entomopathogenic fungus Beauveria bassiana. Microbiol Res 163:148-151 
D'Alessandro M, Turlings TC (2006) Advances and challenges in the identification of volatiles that mediate interactions among plants and arthropods. Analyst 131:24-32

Davis TS, Crippen TL, Hofstetter RW, Tomberlin JK (2013) Microbial volatile emissions as insect semiochemicals. J Chem Ecol 39:840-859

Dodds KJ, Miller DR (2010) Test of nonhost angiosperm volatiles and verbenone to protect trap trees for Sirex noctilio (Hymenoptera: Siricidae) from attacks by bark beetles (Coleoptera: Scolytidae) in the northeastern United States. J Econ Entomol 103:2094-2099

Dzurenko M, Ranger CM, Hulcr J, Galko J, Kanuch P (2021) Origin of non-native Xylosandrus germanus, an invasive pest ambrosia beetle in Europe and North America. J Pest Sci 94:553 562

Egonyu JP, Torto B (2018) Responses of the ambrosia beetle Xylosandrus compactus (Coleoptera: Curculionidea: Scolytinae) to volatile constituents of its symbiotic fungus Fusarium solani (Hypocreales: Nectriaceae). Arthropod-Plant Inter 12:9-20

Galko J, Dzurenko M, Ranger CM, Kulfan J, Kula E, Nikolov C, Zúbrik M, Zach P (2018) Distribution, habitat preference, and management of the invasive ambrosia beetle Xylosandrus germanus (Coleoptera: Curculionidae, Scolytinae) in European forests with emphasis on the West Carpathians. Forests 10:10. https://doi.org/10.3390/ f10010010

Gomez DF, Rabaglia RJ, Fairbanks KE, Hulcr J (2018) North American Xyleborini north of Mexico: a review and key to genera and species (Coleoptera, Curculionidae, Scolytinae). ZooKeys 768:19-68

Holighaus G, Schütz S (2006) Odours of wood decay as semiochemicals for Trypodendron domesticum L. (Col., Scolytidae). Mitteilungen der deutschen Gesellschaft für allgemeine und angewandte Entomologie 15:161-165

Hulcr J, Atkinson TH, Cognato AI, Jordal BH, McKenna DD (2015) Morphology, taxonomy, and phylogenetics of bark beetles. In: Vega FE, Hofstetter RW (eds) Bark beetles: biology and ecology of native and invasive species. Academic, New York, pp 41-84

Hulcr J, Mann R, Stelinski LL (2011) The scent of a partner: ambrosia beetles are attracted to volatiles from their fungal symbionts. J Chem Ecol 37:1374-1377

Hulcr J, Stelinski LL (2017) The ambrosia symbiosis: from evolutionary ecology to practical management. Annu Rev Entomol 62:285-303

Jeleń HH (2003) Use of solid phase microextraction (SPME) for profiling fungal volatile metabolites. Letters Appl Microbiol 36:263-267

Kendra PE, Montgomery WS, Niogret J, Deyrup MA, Guillén L, Epsky ND (2012) Xyleborus glabratus, X. affinis, and X. ferrugineus (Coleoptera: Curculionidae: Scolytinae): Electroantennogram responses to host-based attractants and temporal patterns in hostseeking flight. Env Entomol 41:1597-1605

Kimmerer TW, Kozlowski TT (1982) Ethylene, ethane, acetaldehyde, and ethanol production by plants under stress. Plant Physiol 69: 840-847

Klimetzek D, Köhler J, Vité JP, Kohnle U (1986) Dosage response to ethanol mediates host selection by "secondary" bark beetles. Naturwissenschaften 73:270-272

Kohnle U, Densborn S, Kölsch P, Meyer H, Francke W (1992) E-7methyl-1,6-dioxaspiro[4.5]decane in the chemical communication of European Scolytidae and Nitidulidae. J Appl Entomol 114:187192

Korpi A, Järnberg J, Pasanen AL (2009) Microbial volatile organic compounds. Critical Rev Toxicol 39:139-193

Kostovcik M, Bateman CC, Kolarik M, Stelinski LL, Jordal BH, Hulcr J (2015) The ambrosia symbiosis is specific in some species and promiscuous in others: evidence from community pyrosequencing. ISME J 9:126-138

Kuhns EH, Tribuiani Y, Martini X, Meyer WL, Peña J, Hulcr J, Stelinski LL (2014) Volatiles from the symbiotic fungus Raffaelea lauricola are synergistic with Manuka lures for increased capture of the Redbay ambrosia beetle Xyleborus glabratus. Agric Forest Entomol 16:87-94
Mayers CG, McNew DL, Harrington TC, Roeper RA, Fraedrich SW, Biedermann PH, Castrillo LA, Reed SE (2015) Three genera in the Ceratocystidaceae are the respective symbionts of three independent lineages of ambrosia beetles with large, complex mycangia. Fungal Biol 119:1075-1092

Miller DR, Dodds KJ, Hoebeke ER, Poland TM, Willhite EA (2015) Variation in effects of conophthorin on catches of ambrosia beetles (Coleoptera: Curculionidae: Scolytinae) in ethanol-baited traps in the United States. J Econ Entomol 108:183-191

Morath SU, Hung R, Bennett JW (2012) Fungal volatile organic compounds: a review with emphasis on their biotechnological potential. Fungal Biol Rev 26:73-83

Nielsen MC, Sansom CE, Larsen L, Worner SP, Rostás M, Chapman RB, Butler RC, de Kogel WJ, Davidson MM, Perry NB, Teulon DA (2019) Volatile compounds as insect lures: factors affecting release from passive dispenser systems. New Zealand J Crop Hort Sci 47: 208-223

Niogret J, Montgomery WS, Kendra PE, Heath RR, Epsky ND (2011) Attraction and electroantennogram responses of male Mediterranean fruit fly to volatile chemicals from Persea, Litchi and Ficus wood. J Chem Ecol 37:483-491

Olsson SB, Hansson BS (2013) Electroantennogram and single sensillum recording in insect antennae. In: Touhara $\mathrm{K}$ (ed) Pheromone signaling. Humana Press, Totowa, pp 157-177

Ott E (2007) Chemical ecology, fungal interactions, and forest stand correlations of the exotic Asian ambrosia beetle Xylosandrus crassiusculus (Coleoptera: Scolytinae). M.S. thesis. University of Louisiana, Baton Rouge

Pureswaran DS, Gries R, Borden JH, Pierce HD Jr (2000) Dynamics of pheromone production and communication in the mountain pine beetle, Dendroctonus ponderosae Hopkins, and the pine engraver, Ips pini (say) (Coleoptera: Scolytidae). Chemoecol 10:153-168

Ranger CM, Biedermann PHW, Phuntumart V, Beligala GU, Ghosh S, Palmquist DE, Mueller R, Barnett J, Schultz PB, Reding ME, Benz JP (2018) Symbiont selection via alcohol benefits fungus farming by ambrosia beetles. PNAS 115:4447-4452

Ranger CM, Gorzlancyk AM, Addesso KM, Oliver JB, Reding ME, Schultz PB, Held DW (2014) Conophthorin enhances the electroantennogram and field behavioural response of Xylosandrus germanus (Coleoptera: Curculionidae) to ethanol. Agric For Entomol 16:327-334

Ranger CM, Horst L, Barnett J, Reding ME, Anderson B, Krause CR (2017) Comparative morphology and distribution of antennal sensilla on Xylosandrus germanus and Xylosandrus crassiusculus (Coleoptera: Curculionidae: Scolytinae). Ann Entomol Soc Am 110:172-188

Ranger CM, Reding ME, Addesso K, Ginzel M, Rassati D (2021) Semiochemical-mediated host selection by Xylosandrus spp. ambrosia beetles (Coleoptera: Curculionidae) attacking horticultural tree crops: a review of basic and applied science. Can Entomol 153:103-120

Ranger CM, Reding ME, Gandhi K, Oliver J, Schultz P, Cañas L, Herms D (2011) Species dependent influence of (-)-alpha-pinene on attraction of ambrosia beetles to ethanol-baited traps in nursery agroecosystems. J Econ Entomol 104:574-579

Ranger CM, Reding ME, Persad AB, Herms DA (2010) Ability of stressrelated volatiles to attract and induce attacks by Xylosandrus germanus and other ambrosia beetles (Coleoptera: Curculionidae, Scolytinae). Agric Forest Entomol 12:177-185

Ranger CM, Reding ME, Schultz PB, Oliver JB, Frank SD, Addesso KM, Chong JH, Sampson B, Werle C, Gill S, Krause C (2016) Biology, ecology, and management of nonnative ambrosia beetles (Coleoptera: Curculionidae: Scolytinae) in ornamental plant nurseries. J Int Pest Manag 7:1-23 
Ranger CM, Schultz PB, Frank SD, Chong JH, Reding ME (2015) Nonnative ambrosia beetles as opportunistic exploiters of living but weakened trees. PLoS One 10:e0131496

Rassati D, Contarini M, Ranger CM, Cavaletto G, Rossini L, Speranza S, Faccoli M, Marini L (2020) Fungal pathogen and ethanol affect host selection and colonization success in ambrosia beetles. Agric Forest Entomol 22:1-9

Renwick JAA, Hughes PR, Ty TD (1976) 2-Phenylethanol isolated from bark beetles. Naturwissenschaften 63:1968

Sullivan BT (2005) Electrophysiological and behavioral responses of Dendroctonus frontalis (Coleoptera: Curculionidae) to volatiles infested from conspecifics. J Econ Entomol 98:2067-2078

Sullivan BT, Dalusky MJ, Wakarchuk D, Berisford CW (2007) Field evaluations of potential aggregation inhibitors for the southern pine beetle, Dendroctonus frontalis (Coleoptera: Curculionidae). J Entomol Sci 42:139-149
VanDerLaan N, Ginzel M (2013) The capacity of conophthorin to enhance the attraction of two Xylosandrus species (Coleoptera: Curculionidae: Scolytinae) to ethanol and the efficacy of verbenone as a repellent. Agric Forest Entomol 15:391-397

Vega FE, Biedermann PH (2020) On interactions, associations, mycetangia, mutualists and symbiotes in insect-fungus symbioses. Fungal Ecol 44:100909. https://doi.org/10.1016/j.funeco.2019. 100909

Webster B, Bruce T, Pickett J, Hardie J (2008) Olfactory recognition of host plants in the absence of host-specific volatile compounds: host location in the black bean aphid, Aphis fabae. Comm Integ Biol 1: 167-169

Wingfield MJ, Barnes I, de Beer ZW, Roux J, Wingfield BD, Taerum SJ (2017) Novel associations between ophiostomatoid fungi, insects and tree hosts: current status - future prospects. Biol Inv 19:32153228 